\title{
AS POSSIBILIDADES DA HISTÓRIA DA ARTE NUM ACERVO PRIVADO: A EXPERIÊNCIA DA COLEÇÃO BRASILIANA / FUNDAÇÃO ESTUDAR
}

\section{Valéria Piccoli}

Núcleo de Pesquisa em Crítica e História da Arte - Pinacoteca do Estado de São Paulo

Ainda no ano de 2007, será formalizada a doação das cerca de 500 obras que compõem a Coleção Brasiliana / Fundação Estudar à Pinacoteca do Estado de São Paulo. Nesta oportunidade, será concluído um percurso de dez anos de atividades em torno desse acervo, percurso este que se constitui numa experiência bastante singular no contexto do colecionismo no Brasil. O objetivo da presente comunicação é relatar essa experiência, conduzida desde o início por Carlos Martins - artista plástico e museólogo, com significativa atuação na área cultural, tendo sido diretor dos Museus Castro Maya, no Rio de Janeiro -, e da qual participei como pesquisadora e curadora assistente desde 1997.

A Coleção Brasiliana é atualmente um acervo privado, mantido pela Fundação Estudar, e composto por pinturas, aquarelas, desenhos e gravuras de temática brasileira, datadas em sua maioria do século XIX, ainda que compreenda também algumas peças isoladas dos séculos XVII e XVIII. Entre seus autores destacam-se os artistas europeus, que estiveram de passagem pelo Brasil ou aqui residiram, assim como artistas brasileiros das primeiras gerações formadas pela Academia Imperial de Belas Artes. Em grande parte, as obras da Coleção Brasiliana integram o universo iconográfico do que se convencionou chamar de artistas viajantes. Destaco aqui, como exemplos da diversidade de origem, formação e propósitos dos artistas presentes no acervo, o retrato Marquesa de Belas de Nicolas Antoine Taunay (1755-1830), pintor de formação acadêmica francesa, que chegou ao Brasil em 1816 integrando a Missão Artística, e viveu no Rio de Janeiro até 1821; uma aquarela de Benjamin Mary (1792-1847), diplomata, botânico diletante e artista autodidata, que foi o representante diplomático do Reino da Bélgica no Brasil, autor de curioso panorama do Rio de Janeiro tomado de Santa Tereza, com cerca de três metros de comprimento; a Natureza morta com flores do pintor brasileiro Agostinho José da Motta (1824-1878), aluno e posteriormente professor da Academia Imperial de Belas Artes; e Enseada de Paquetá de Nicolau Facchinetti (1824-1900), pintor de paisagens de origem italiana, radicado no Rio de Janeiro a partir de 1849. Como é 
possível notar por essa breve amostra, o acervo possui exemplos significativos dos principais gêneros da arte oitocentista, como o retrato, a pintura de paisagem, a natureza morta, assim como a pintura histórica, representada na Coleção Brasiliana por tela Jean-Baptiste Debret (17681848), entre outras.

A Coleção Brasiliana teve origem num conjunto de obras adquirido em 1996 dos herdeiros do colecionador e antiquário Jacques Kugel (19121985), personalidade bastante conhecida do mercado de arte francês. Nascido em 1912 em Minsk, na atual Bielorússia, Kugel pertencia a uma tradicional família judaica de antiquários, que havia se radicado em Paris a partir de 1925, escapando da revolução bolchevique. Quando da ocupação de Paris pelas tropas alemãs durante a Segunda Guerra, a família sofreria um novo revés, sendo obrigada deixar a França. Os Kugel teriam imigrado para Portugal levando na bagagem objetos de arte e jóias. Jacques Kugel acabaria por casar-se em Lisboa com a poetisa Merícia de Lemos (19131996).

Nesses anos de guerra vividos em Portugal, Kugel daria início, então, à aquisição de obras de temas brasileiros das quais nunca se desfaria e que seriam o germe da Coleção Brasiliana. Sabemos que naquele momento, apresentavam-se oportunidades no mercado de arte que propiciaram o incremento e a formação de diversas coleções em vários países do mundo, oportunidades essas às quais Kugel, como um experiente marchand, esteve, sem dúvida, bastante atento. Já de volta a Paris em 1955, encontramos um indício da importância que alcançara então sua coleção na colaboração prestada por ele aos Archives Nationales, organizadores, naquele ano, de uma exposição sobre as relações culturais entre a França e o Brasil desde o século XVI. No catálogo desta mostra, que aconteceu no Hotel de Rohan em Paris, figuram cerca de 30 obras que pertenciam à coleção particular de Kugel, entre elas algumas telas de Frans Post (16121680), além de objetos pessoais que haviam pertencido a membros da família imperial brasileira. Destas obras emprestadas por Kugel à exposição France et Brésil, oito integram ainda hoje o acervo da Coleção Brasiliana.

Adquirida, portanto, na França em 1996, a coleção ainda inédita no Brasil ingressou no país no ano seguinte em regime de comodato, sob responsabilidade da Fundação Estudar. A Fundação Estudar é uma entidade sem fins lucrativos, que fornece bolsas de estudo e auxílio ao 
desenvolvimento de carreiras nas áreas de administração e finanças. Tratase de uma instituição sem perfil cultural, mas que por disposição estatutária foi a figura jurídica que tornou possível a entrada do acervo no país. A partir de 1997, ela passou a ocupar-se da administração da Coleção Brasiliana e de sua equipe.

A decisão de situar a coleção em São Paulo, onde existem poucos acervos com este perfil abertos à visitação pública, foi determinante para o estabelecimento das propostas de atuação em torno da Coleção Brasiliana. A mais importante dessas propostas foi uma deliberada opção por não destinar um edifício próprio para abrigar o acervo, mas, ao contrário, buscar soluções de parcerias com instituições possuidoras de acervos afins. A adoção deste partido (e aqui tomo de empréstimo uma palavra do vocabulário da arquitetura) fundou-se na convicção de que é necessário no Brasil trabalhar para o fortalecimento das instituições culturais existentes, tentando evitar, na medida do possível, a dispersão de esforços. Mas, sobretudo, ele diz respeito a um princípio que foi para nós norteador nas mais diversas etapas do trabalho: o de entender este acervo não como um conjunto que se completa em si mesmo, mas encará-lo sempre como parte de um universo iconográfico maior, que só teria a ganhar em sentido no diálogo com outras coleções. Quando da chegada do acervo ao Brasil, a alternativa de parceria que se apresentou como a mais viável foi a Fundação Maria Luisa e Oscar Americano. Esta instituição, em funcionamento desde 1974, tem sede no bairro do Morumbi em São Paulo, na antiga residência do engenheiro Oscar Americano (1908-1974) projetada, em 1950, pelo arquiteto paulista Oswaldo Bratke (1907-1997). A Fundação Maria Luisa e Oscar Americano possui um acervo de arte brasileira, constituído de mobiliário, prataria e porcelanas, além de esculturas e pinturas de artistas como Frans Post, Alberto da Veiga Guignard (1896-1962) e Cândido Portinari (1903-1962). Neste caso, a parceria se deu numa base de permuta, ou seja, a Fundação Estudar construiu uma reserva técnica na sede da Fundação Oscar Americano e, em contrapartida, nos foi permitido usar durante um determinado período de tempo, além dessa reserva, uma sala de trabalho.

Uma vez definidas as condições para o abrigo da coleção, principiaram também as tratativas para internação do acervo no país, que não detalho aqui. Assim que as peças chegaram a São Paulo, deu-se início a uma série de procedimentos de caráter museológico que visavam preparar a 
Coleção Brasiliana para ser apresentada ao público brasileiro. Lembro que, do ponto de vista da conservação das obras, uma primeira etapa de trabalho já havia sido cumprida na França, onde as peças que apresentavam condições mais frágeis de conservação foram restauradas antes da viagem ao Brasil. Em São Paulo, a primeira fase efetivamente de trabalho foi dedicada ao adequado acondicionamento das obras, assim como a providências relativas ao restauro e conservação das demais, da qual tomou parte ativa Ana Paula de Camargo Lima, integrante da equipe naquele momento. Simultaneamente, começou a ser preparada a primeira mostra do acervo, que aconteceu em 1998 na sede da Fundação Maria Luisa e Oscar Americano. Foi uma pequena exposição de apenas 28 obras, destinada a marcar tanto a parceria entre as duas fundações, como a chegada da Coleção Brasiliana ao país.

Antes de iniciar as etapas de tombamento e classificação do acervo - e aqui passo a me referir mais detalhadamente às atividades de pesquisa procedeu-se a consultas junto a diversas instituições museológicas para chegar à elaboração de ficha catalográfica adequada ao armazenamento das informações técnicas e de pesquisa sobre o acervo. Da mesma forma, foi configurado um modelo de banco de dados informatizado, habilitado a cruzar informações sobre artistas, obras, bibliografia, exposições, entre outros.

Por fim, demos início propriamente ao tombamento das obras, durante o qual foi necessário verificar atentamente assinaturas, inscrições, datações, reexaminar, enfim, todos os dados que pudessem contribuir para a confirmação ou contestação de atribuições já assumidas anteriormente. Nesse sentido, lembro que o que tinha sido disponibilizado para a equipe antes da chegada do acervo ao Brasil eram dois volumes encadernados em espiral, um deles denominado "Lista de óleos" e o outro, "Gravuras e mapas". Para ilustrar um pouco o que foi esse processo de tombamento, destaco a aquarela que deu entrada no acervo da Coleção Brasiliana como sendo de autoria do artista inglês David Roberts (1796-1864). Na referência feita a ela no volume "Gravuras e mapas", lia-se: "Roberts foi um dos artistas ingleses mais famosos de seu tempo, mais conhecido pelos seus temas orientalistas, como vistas da Síria e do Egito. Esta parece ser a única obra conhecida de Roberts de tema brasileiro". Na verificação feita no Brasil, retirada a obra de sua montagem original, notou-se que a aquarela era assinada no verso com o monograma "WGO", que constatamos ser do 
diplomata inglês e artista amador William Gore Ouseley (1797-1866), a quem foi, a partir de então, atribuída a autoria da peça. A imagem corresponde ainda a uma das gravuras do livro Views in South America, que Ouseley publicou em Londres, em 1852.

Outro exemplo semelhante para o qual chamo a atenção ocorreu com a retificação de autoria da tela Grande cascata da Tijuca, atribuída na coleção Kugel ao pintor Louis-Auguste Moreau (1817-1877). A obra trazia no verso uma espécie de etiqueta com a seguinte inscrição: "L.A.Moreaux, Lembrança da América”. Além disso, há também uma inscrição legível sobre a pedra na lateral esquerda da pintura, que diz: "A M Moreaux souvenir de la mère de l'eau". Na nossa citada "Lista de óleos", a obra era referida pelo seguinte verbete: “Obra característica deste pintor, irmão de René Moreaux, também ativo como pintor no Brasil. Fixados inicialmente em Pernambuco, desde 1838, embarcaram posteriormente para o Rio de Janeiro, onde morreram". No entanto, a tela apresentava assinatura e datação visíveis na parte lateral direita, próximo à figura do pássaro: “Araújo, 1833". Através de estudos comparativos, foi possível notar que a assinatura correspondia à usada por Manuel de Araújo Porto Alegre (18061879) em desenhos conservados no Museu Julio de Castilhos, em Porto Alegre. Naturalmente, a inscrição sobre a pedra era uma dedicatória e havia sido tomada enganosamente como assinatura da obra.

Eu poderia me estender aqui, já que há vários casos como esses ocorridos no processo de tombamento, que envolveram seja correção de atribuição e/ou datação, seja identificação equivocada de locais representados. Mas cumprida esta etapa de tratamento geral das informações técnicas sobre as obras, que foram devidamente inseridas no banco de dados, chegou-se a uma primeira listagem já mais criteriosa da Coleção Brasiliana. Foi possível, então, iniciar a pesquisa de campo, para o que foi constituída uma equipe de pesquisadores que levaram a cabo um extenso trabalho de coleta de dados junto a museus, bibliotecas e coleções privadas no Brasil, assim como em diversas instituições no exterior, visando a correção de dados biográficos e identificação mais precisa das imagens representadas. Privilegiou-se, da mesma forma, a coleta de imagens de outras obras dos mesmos autores que pudessem situar a peça do acervo da Coleção Brasiliana num contexto mais geral da produção do artista estudado. Entre os membros da equipe de pesquisa, gostaria de nomear especialmente, além da própria Ana Paula, que também fez as vezes de 
pesquisadora, Renato Palumbo Doria, que por bastante tempo foi uma espécie de "sucursal" da Coleção Brasiliana no Rio de Janeiro, bem como Renata Bittencourt e Gabriela Aidar, que, em etapas diferentes, tiveram um atuação bastante importante no contexto deste projeto.

Há também histórias curiosas propiciadas pelo contato com instituições no exterior. Cito aqui o caso da pintura Paisagem com farol, assinada pelo artista alemão Eduard Hildebrandt (1818-1869). Na tentativa de identificar que trecho do litoral brasileiro teria sido registrado pelo artista nessa obra, buscou-se contato com o Kupferstischkabinett do Staatliche Muzeen zu Berlin, Alemanha, onde está conservada a maior parte dos desenhos de sua autoria. Através de um estudo comparativo, foi possível identificar o local representado na obra como sendo um farol em Galle, no sudoeste do Sri Lanka, por onde o artista teria passado no curso da viagem que empreendeu pela Índia, China e Japão, entre 1862 e 1864. A pintura foi realizada, portanto, quase 20 anos após a estadia de Hildebrandt no Brasil.

Outra dessas histórias diz respeito a um conjunto de 22 aquarelas que documentam uma travessia do Atlântico desde a França, chegando ao Rio de Janeiro e Bahia. Uma das aquarelas era claramente um projeto de frontispíco de livro, onde se lia o título, "Traversée de Toulon à Rio de Janeiro”, e a data, “1837”. Na coleção Kugel, as obras eram atribuídas a um certo Linety, e a leitura da assinatura poderia sugerir de fato que esse fosse o nome do artista. Na tentativa de identificá-lo, contatamos o Service Historique de la Marine Française. Depois de uma intensa troca de correspondências, foi localizado nesse arquivo o dossiê de um marinheiro de nome Jules de Sinety (1812-?), que, a bordo da corveta L'Expéditive, havia participado entre 1837 e 1841 do bloqueio anglo-francês ao Rio da Prata, o que correspondia exatamente aos dados que puderam ser extraídos das aquarelas. Recentemente, tivemos ainda a surpresa de ter sido adquirido no mercado francês um diário de Sinety referente à mesma viagem ao Prata. O comprador argentino entrou em contato com a Coleção Brasiliana no intuito de organizar uma publicação sobre esse marinheiro-artista, que deve vir a público em breve.

O caso que envolve o nome do artista Nicolau Facchinetti é também elucidativo desse período de correspondências com outras instituições e pesquisadores. A historiadora Maria Pace Chiavari, por facilidades pessoais, conseguiu acesso na Itália ao documento de 
nascimento deste pintor, natural de Treviso, em que se atesta o nome de batismo "Niccolò Agostino", o que contesta a historiografia brasileira que tradicionalmente o nomeia "Nicolau Antonio". De posse desta informação, nos propusemos a retraçar a origem do engano. Chegamos, assim, a Laudelino Freire, que, em 1916, no livro Um século de pintura, chama Facchinetti pela primeira vez de Nicolau Antonio. Contudo, ainda que a certidão de nascimento de Facchinetti tenha sido publicada como ilustração do texto escrito por Maria Pace Chiavari no catálogo da exposição retrospectiva organizada por Carlos Martins e por mim no Centro Cultural do Banco do Brasil no Rio de Janeiro em 2005, o artista ainda continua sendo chamado de Nicolau Antonio Facchinetti.

Decorre de todo esse trabalho conjunto a constituição de um banco de dados e de arquivos de pesquisa abertos à consulta de interessados, e que foram responsáveis por fornecer subsídios para propostas de exposições, publicações e atividades educativas em torno do acervo da Coleção Brasiliana. Nosso foco, nas diversas etapas deste processo, foi tentar definir o valor artístico e histórico de cada obra, trabalho que está documentado no primeiro catálogo publicado sobre a Coleção Brasiliana, Revelando um acervo (São Paulo: BEI, 2000). Nesta edição, contamos ainda com textos de autores convidados, como o historiador holandês e brasilianista Ernst van den Boogaart, que escreveu um instigante ensaio sobre o par de alegorias de América e África que integram o acervo; de Caroline d'Assay, restauradora francesa responsável pela recuperação da Revista das tropas na Praia Grande de Debret, que descreve e documenta o tratamento dado à pintura; do historiador João Hermes Pereira de Araújo, que também aborda a obra de Debret, mas do ponto de vista da descrição do fato histórico; e, por último, de Bernard Jacqué, diretor do Musée du Papier Peint, a antiga manufatura Zuber em Rixheim, na França, que se refere aos métodos de fabricação e comercialização do papel de parede panorâmico Vistas do Brasil, de que a Coleção Brasiliana possui um exemplar impresso em 1829.

Ao conjunto inicial proveniente da coleção Kugel, foram acrescidas, ao longo dos anos, outras obras, com o intuito de que, paulatinamente, as inevitáveis lacunas do acervo fossem preenchidas. Isso motivou a edição de um novo catálogo, publicado em 2006, intitulado Coleção Brasiliana Fundação Estudar. Novamente, colegas historiadores foram convidados a refletir sobre o acervo, organizado, nesta oportunidade, em 
segmentos temáticos. Os autores deste catálogo são: Beatriz Siqueira Bueno, que escreve sobre a presença da cartografia na Coleção Brasiliana; Vera Beatriz Siqueira, que apresenta um texto sobre "Iconografia e Paisagem"; Rafael Cardoso, que aborda as gravuras dos livros de viagens pitorescas; além de Luciano Migliaccio, que se detem nos retratos e cenas históricas presentes na coleção. Quando da elaboração do projeto desta publicação, pretendia-se que o livro pudesse trazer a público uma catalogação completa do acervo. Contudo, após a finalização do catálogo, ocorreram ainda as aquisições dos volumes da Viagem pitoresca e histórica ao Brasil de Debret e da edição francesa do livro de viagem do príncipe Maximilian zu Wied-Neuwied (1782-1867), que se somaram então ao conjunto original de obras.

Em diversas oportunidades, a Coleção Brasiliana foi apresentada de modo abrangente em exposições, caracterizando a contribuição trazida pelo acervo para ampliar o escopo da iconografia dos viajantes sobre o Brasil. Destaco aqui, as exposições ocorridas no Paço Imperial, Rio de Janeiro, em 1999, no contexto da mostra O Brasil Redescoberto, e no ano seguinte na Pinacoteca do Estado, em São Paulo. Da mesma forma, obras da coleção têm sido solicitadas para compor mostras organizadas por instituições culturais no Brasil e exterior. Em 2002, reconhecida sua relevância artística e histórica, a Coleção Brasiliana foi doada em definitivo à Fundação Estudar, e incorporada ao patrimônio cultural brasileiro. Neste mesmo ano, um convênio foi firmado entre a Secretaria de Estado da Cultura de São Paulo e a Fundação Estudar prevendo a apresentação de obras da Coleção Brasiliana na Pinacoteca do Estado por meio de exposições de longa duração, sob diferentes recortes temáticos e acompanhadas por programas educativos especialmente elaborados. Estas mostras, além de proporcionarem uma apreciação do acervo da Coleção Brasiliana, tinham também por objetivo oferecer uma introdução à exposição de arte brasileira dos séculos XIX e XX da coleção permanente do museu. Nesse contexto, foram realizadas as mostras Vistas do Brasil (2003-2005) e A figura humana em representação (2005-2006).

Vistas do Brasil foi um projeto experimental desenvolvido conjuntamente entre a equipe da Coleção Brasiliana e a equipe de Ação Educativa da Pinacoteca do Estado, que se propunha a explorar as possibilidades de interação entre museologia, história da arte e ação 
educativa. A exposição centrava-se na representação da paisagem brasileira pelos artistas viajantes, tomada na dupla mão da contextualização da prática do registro da paisagem como continuação de uma tradição européia, e da introdução do gênero da paisagem no contexto da arte brasileira. Assim, a exposição investigava os diferentes modelos e intenções que presidiam a representação da paisagem do Brasil, assunto tão caro à arte brasileira do oitocentos. Já desde seu processo de conceituação, o projeto de Vistas do Brasil contemplava diversas formas de mediação para atender a diferentes demandas relativas à faixa etária dos visitantes, assim como a graus diversos de interesse e envolvimento com o assunto. Recursos educativos em formato multimídia, de folders de visita e áudio-guias, foram então pensados e desenvolvidos pelas educadoras Mila Chiovatto e Gabriela Aidar. Contamos ainda com a participação de especialistas, convidados a conduzir visitas que propusessem outras abordagens de leitura para a mesma exposição. Este programa, chamado Arte em Prosa, contou com a participação dos artistas Cláudio Mubarac e Sergio Fingermann, da educadora Denise Grinspum, das conservadoras Lucia Thomé e Ana Scaglianti, do curador Felipe Chaimovich e do historiador Jorge Coli. Essa iniciativa foi marcada pela intenção de que a Coleção Brasiliana fosse também um espaço de intercâmbio, e estivesse aberta à interlocução com estudiosos e interessados pela iconografia brasileira do século XIX. Cumprindo um antigo propósito de fazer circular o acervo da Coleção Brasiliana por outros espaços institucionais do Brasil, preferencialmente fora do eixo Rio-São Paulo, esta exposição será remontada em maio de 2008, no Museu de Arte do Espírito Santo, em Vitória.

A figura humana em representação foi a segunda exposição realizada no âmbito do convênio com a Pinacoteca do Estado e propunha um confronto entre o gênero do retrato, em que a fidelidade ao modelo se apresenta como a condição essencial de seu sucesso, e a figura humana enquanto veículo de idéias abstratas na constituição de pinturas de figuras alegóricas. Um pouco mais modesta com relação à sua antecessora, contudo, esta exposição contou também com recursos multimídia desenvolvidos especialmente para aprofundar alguns conteúdos relativos às obras expostas, principalmente no que se refere às representações alegóricas.

O programa de divulgação do acervo prosseguiu com mostras realizadas também no exterior. Em 2005, a Coleção Brasiliana foi escolhida 
pelo diretor do Musée de la Vie Romantique em Paris para constituir a exposição sobre o século XIX brasileiro no contexto de Brésil Brésils, o Ano do Brasil na França. A mostra La Collection Brasiliana: les peintres voyageurs romantiques au Brésil (1820-1870) foi apresentada de junho a novembro naquela instituição. A ocasião revestiu-se de especial interesse, na medida em que caracterizava o retorno de um conjunto de obras que havia sido constituído como uma coleção privada na França, e era apresentada pela primeira vez ao público daquele país. De Paris, a exposição seguiu para Portugal, onde foi mostrada no Museu Nacional de Soares dos Reis, no Porto, e na Galeria de Pintura do Palácio Nacional da Ajuda, em Lisboa. Em todas essas ocasiões, obras afins de acervos locais foram adicionadas à exposição, na intenção de estabelecer possíveis diálogos entre obras que se encontram, de outra forma, dispersas.

Por fim, a inauguração da próxima mostra da coleção na Pinacoteca do Estado virá celebrar o momento em que a Coleção Brasiliana passará a pertencer a uma instituição pública. O acervo da Pinacoteca do Estado de São Paulo, centrado na produção brasileira de meados do século XIX até a atualidade, será assim acrescido de um conjunto de obras que amplia significativamente o espectro de sua abrangência temporal. O percurso proposto e pretendido para a Coleção Brasiliana a partir de diálogos e intercâmbios conclui-se assim numa incorporação que, esperamos, possa propiciar sempre a existência de espaços de reflexão e estudo sobre a arte brasileira do século XIX.

\section{Bibliografia}

MARTINS, Carlos (org.) Revelando um acervo. São Paulo: BEI, 2000.

MARTINS, Carlos (org.) Coleção Brasiliana / Fundação Estudar. São Paulo: Via Impressa, 2006.

La Collection Brasiliana. Les peintres voyageurs romantiques au Brésil. Paris: Musée de la vie romantique, 2005 (catálogo de exposição).

MARTINS, Carlos (org.) O Brasil redescoberto. Rio de Janeiro: Paço Imperial, 1999 (catálogo de exposição). 